\title{
Effect of annealed temperature on some structural, optical and mechanical properties of selenium thin film
}

\author{
Alaa A. Abdul-Hamead \\ Department of Material Engineering, University of Technology \\ E-mail: adr.alaa@yahoo.com
}

\begin{abstract}
In this paper a thin films of selenium was prepare on substrates of $\mathrm{n}-\mathrm{Si}$ by evaporation in a vacuum technique with thickness about $0.5 \mu \mathrm{m}$. And then an annealing process was done on samples at two temperature (100 and 200) $\mathrm{C}^{\circ}$ in a vacuum furnace $\left(10^{-3}\right.$ torr).

Some structural, optical and mechanical properties of prepared thin films were measured. Results showed that the prepared film was the crystallization, optical transmittance and micro hardness of the prepared thin films increased significantly after annealing.
\end{abstract}

Key words

selenium, thin film, transmittance, annealing, $X R D$.
Article info.

Received: Apr. 2014

Accepted: Jun. 2014

Published: Sep. 2014

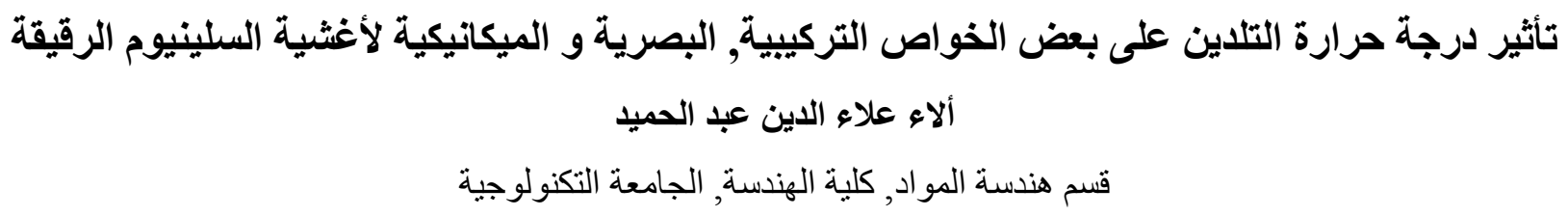



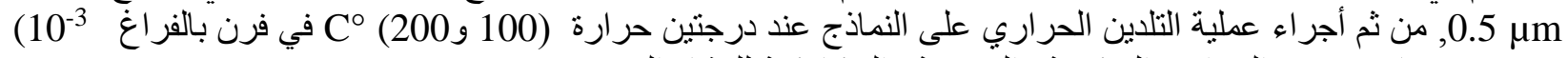
torr) أظهرت النتائج بأن الاغشيه المحضرة كانت متبلورة, و النفاذية البصرية و الصلادة ل للأغشية المحضرة ارتفعت بعد التبلور الأي تحسن بشكل ملحوظ بعد التلدين.

\section{Introduction}

Selenium is known as an essential element for life due to its great nutritional effect and many fascinating properties in biology ,chemistry and physical sciences: for example, protecting cells against the effects of free radicals that are produced during normal oxygen metabolism, reinforcing the normal functions of the immune system and thyroid gland, localizing malfunction in the pancreas, and the safe uses of selenium in agriculture and in the biosciences [1].
Amorphous (semiconducting) selenium is used for electro-static imaging, as well as for photovoltaic cells, in the visible region of the electromagnetic spectrum. The photoconductive properties determine how effective and fast responding the material will be; that is, the higher the mobility, the faster the response and the faster the material can be optically scanned. It is hoped that $a$ study of the photoconductive properties will lead to more efficient materials. In addition, it would be of practical importance to develop materials 
sensitive over a wide region of wavelengths [2].Methods for fabrication of thin films in general and selenium particularly such as evaporation, electroplating spray pyrolysis etc. $[3,4]$.

Fella et al. [5] study sodium assisted sintering of chalcogenides and its application to solution processed $\mathrm{Cu}_{2} \mathrm{ZnSn}(\mathrm{S}, \mathrm{Se})_{4}$. Demonstrate thin film solar cells were improvement in grain growth in the presence of sodium. It enhances the surface chemisorption of selenium molecules and can promote the formation of liquid $\mathrm{Na}_{2} \mathrm{Se}_{\mathrm{x}}$ phases during reactive annealing of the precursor.

$\mathrm{Lu}$ et al. [6], fabrication of flexible thermoelectric Se thin film devices for ink jet printing by using thermo electric nanomaterials successfully serve power generation and cooling. Tan [7], study renewed interest in the electrical and optical properties of selenium films due to its use as an ultra-sensitive photoconductor in the newly developed flat panel x-ray image detector and high definition digital and video camera. This project has examined the optical properties of a range of Se films fabricated by conventional vacuum deposition technique. Cabral et al. [8], study Nano gravimetric study of lead under potential deposition of selenium thin films as a semiconductor alloy formation procedure, an electrochemical quartz crystal, microbalance $\mathrm{Au}$ electrode modified with a Se thin film was used to investigate the electrochemical behavior of lead atoms using under potential deposition (UPD) conditions. These findings offer a new strategy for alloy formation in semiconductor films using an effective tool to quantify the exact amount of the incorporated metal.

The goals of this paper are to fabrication selenium thin film by evaporation technique, and study some of structural, optical and mechanical properties, and the effect of annealing in a vacuum.

\section{Experimental work \\ Practical includes:}

a. Preparation of substrates:

The substrates that used is laboratory glass sheet slides with diminutions of in standard dimension as $(5 \times 2 \times 0.2) \mathrm{cm}$ and purity (99.99\%), and clean by Distilled water and alcohol $99 \%$ and dying in air. $\mathrm{n}-\mathrm{Si}$ $(1 * 1 * 0.2) \mathrm{mm}$ was cleaned with $\mathrm{Cp}-4$ solution(Nitric acid, hydrofluoric acid and acetic acid and ratios (3:2:3)) for (10) min.

b. Material:

Selenium pure powder (99.99\%) was used to fabrication thin films.

c. Preparing thin film :

Using thermal vacuum evaporation system type EDWARDS with Mo- boat. Fig.1, deposition rate was $2 \mathrm{~nm} / \mathrm{sec}$ at $10^{-3}$ torr. The distance from the substrate to evaporation source about $(12 \mathrm{~cm})$, the coating thickness accurately by eqs(1 and 2) [9], and it was $0.5 \pm 0.01 \mu \mathrm{m}$ :

$\mathrm{T}=\left(1-\mathrm{R}^{2}\right) * \mathrm{e}^{-\alpha \mathrm{t}}$

and

$\mathrm{R}=(\mathrm{n}-1)^{2} /(\mathrm{n}+1)^{2}$

where

T: Optical transmittance

$\mathrm{n}$ : Refractive index

$\alpha$ : Absorption coefficient

t: coat thickness

d. Annealing process:

At vacuum furnace type (IVOCLAR), Fig.2, the samples were annealed for $30 \mathrm{~min}$ in 100 and $200 \mathrm{C}^{\circ}$, in addition to as deposited sample basically.

e. Testing

1- X-ray diffraction with diffractometer type $\mathrm{CuK} \alpha(\lambda=1.5406 \AA)$. This test is carried out in Advanced Materials Research Center at the Technology and Science Ministry, the scanning speed was 3\%. . To 
determine the (a- lattice constant) from $\mathrm{X}$ ray spectrum were using the following formulas were used for hexagonal crystal system [10] which is a relationship between the d-spacing and lattice constants:

$$
1 / \mathrm{d}^{2}=(4 / 3)\left[\left(\mathrm{h}^{2}+\mathrm{hk}+\mathrm{k}^{2}\right) / \mathrm{a}^{2}\right]+\mathrm{l}^{2} / \mathrm{c}^{2}
$$
where $\mathrm{h}, \mathrm{k}$, and $\mathrm{l}$, are known as the Miller indices (hkl) and are used to identify each lattice plane.

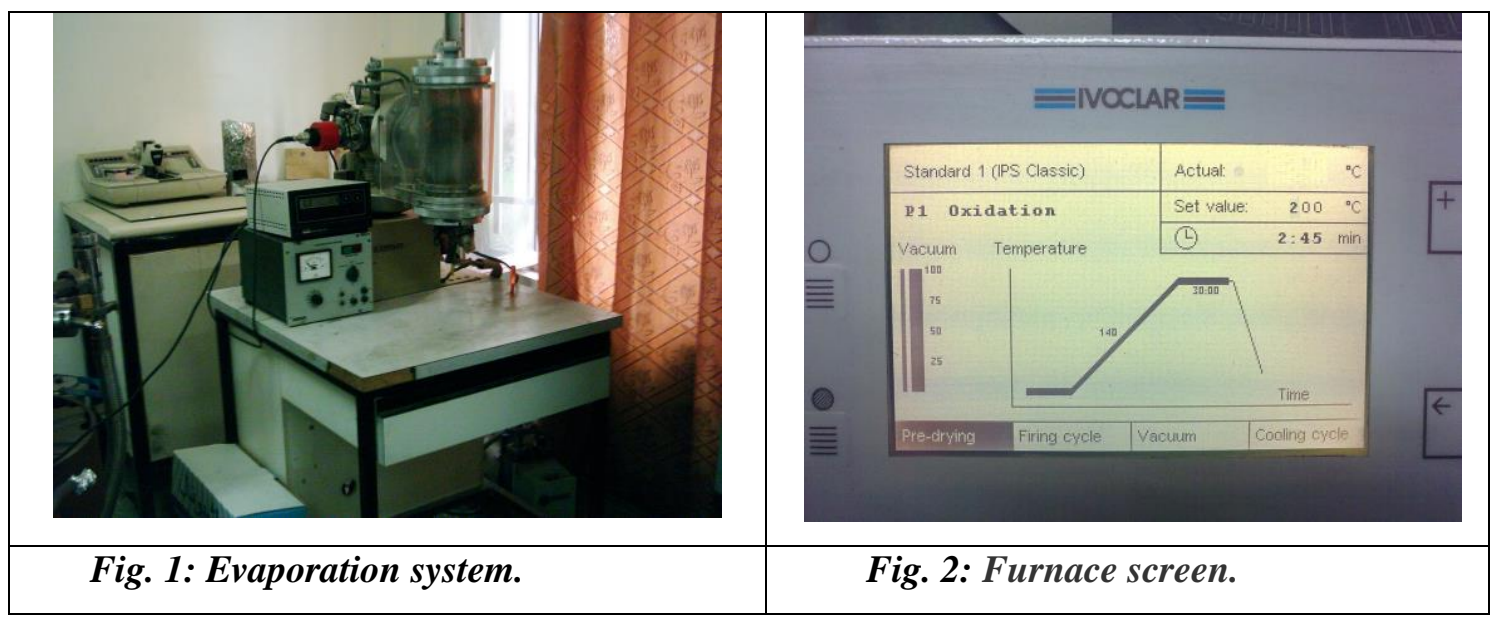

2- The optical microscopic test of the prepared film using a microscope type (permable) $100 \mathrm{X}$ can be used to characterize information on the structural morphology of the film. The test was carrying out in Nanotechnology and Advanced Materials Research Center / the University of Technology.

3- The prepared film were examined by using Scanning Electron Microscope (SEM) type (S-4160 Hitachi, Japan) at university of Tehran/Iran.

4- UV- VIB test by using spectrophotometer (CECIL7200) from (500-700 nm).

5- Measuring Hardness: Microhardness was measured using a device of the type (microscope universal research) Load amount $(5 \mathrm{gm})$ for $5 \mathrm{sec}$ was calculated hardness of Eq. (4):

$$
\text { M.H.V }=\frac{1854.4 P}{t^{2}}
$$

where :

M.H.V: Vickers microhardness
P: load

$\mathrm{t}$ :diameter trace generated

\section{Results and discussion}

Fig. 3 shows diffraction patterns of XRD results chart for Se films as-deposited and after annealing at different temperature. The (JCPDS) database was used to evaluate the XRD response, card (No. 27-0601), and the data of the figures were listed in Table 1.

It was evident after this procedure that the diffraction peaks of the film are a combined response of Se. The structure of $\mathrm{Se}$ is hexagonal polycrystalline and the lattice constant is listed in Table 2.

Without annealing crystallization does not occur, by annealing crystallization arise. With increased annealing temperature lattice constants approaching towards so the standard values as shows in Table 2 and in particular the values of lattice constant c. It can be notice that the increase of annealing temperature increased the degree of crystallization [7,11], as can see from Fig. 3, average grain size was estimated using the 
Scherrer's formula[12], and it was $0.05 \mathrm{~nm}$ for film annealed at $100 \mathrm{C}^{\circ}$ and $(0.151) \mathrm{nm}$ for film annealed at $200 \mathrm{C}^{\circ}$.

$\mathrm{g}=(0.94 \lambda) /\left[\Delta_{(2 \theta)} \cos \theta\right]$ where : $\lambda$ : is the x-ray wavelength $(\AA)$.

$\Delta(2 \theta)$ : FWHM ( radian ).

$\theta$ : Bragg diffraction angle of the XRD peak (degree).

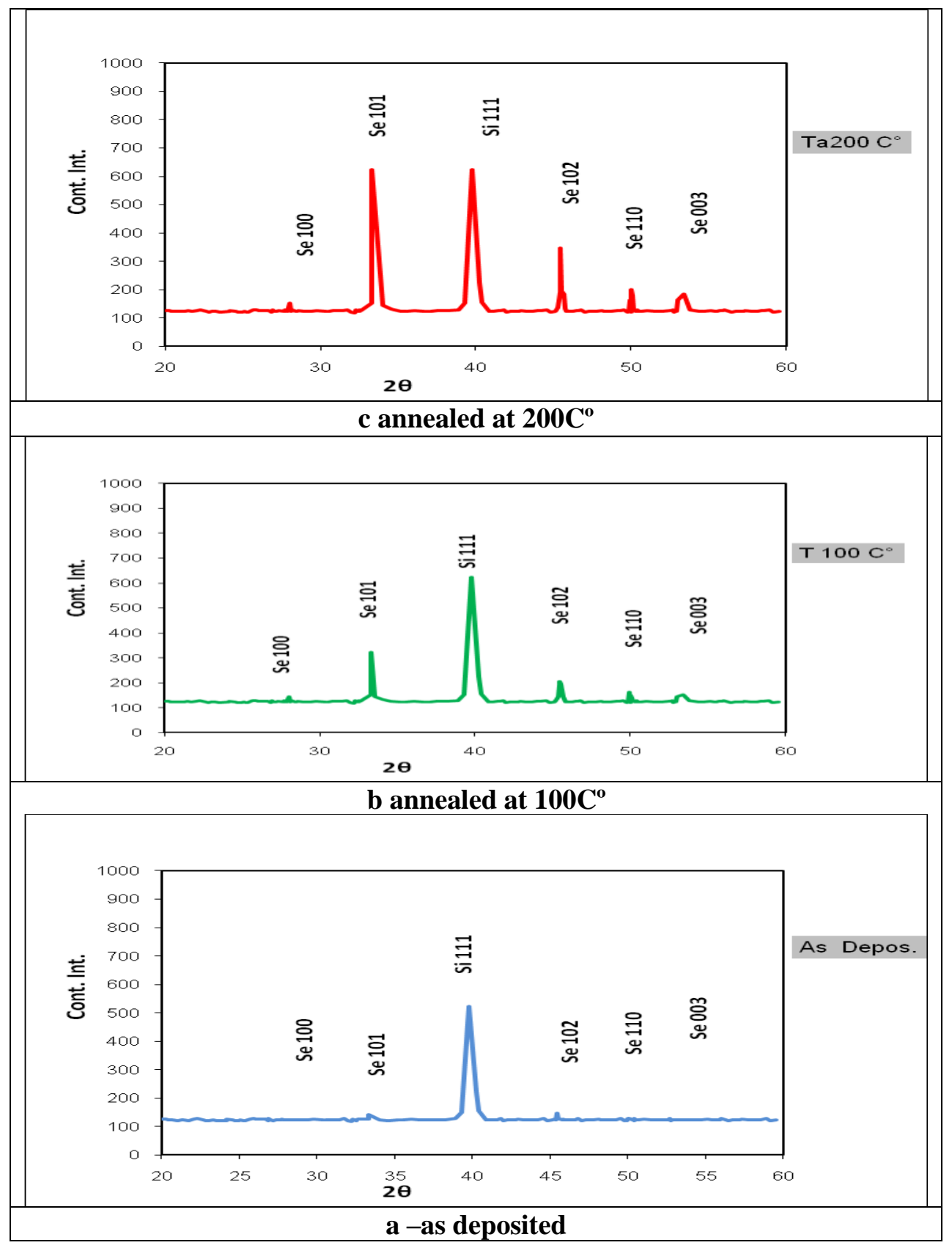

Fig. 3: XRD of selenium thin film at different annealing temperature. 
Table 1: XRD data selenium thin film as depositedand annealed at different temperature.

\begin{tabular}{|c|c|c|c|c|c|c|c|}
\hline \multicolumn{2}{|c|}{ No. 27-0601 } & \multicolumn{6}{|c|}{$T C^{\circ}$} \\
\hline \multirow{2}{*}{$2 \theta_{A S T M}$} & \multirow{2}{*}{$I_{A S T M} \%$} & \multicolumn{2}{|c|}{ R.T } & \multicolumn{2}{|c|}{100} & \multicolumn{2}{|c|}{200} \\
\hline & & $2 \theta_{m}$ & $I_{m} \%$ & $2 \theta_{m}$ & $I_{m} \%$ & $2 \theta_{m}$ & $I_{m} \%$ \\
\hline 28.036 & 10 & -- & -- & 28.032 & 3.4 & 28.034 & 7 \\
\hline 33.330 & 100 & 33.30 & $5 \%$ & 33.318 & 100 & 33.325 & 100 \\
\hline 45.473 & 50 & 45.42 & $4 \%$ & 45.429 & 26 & 45.429 & 45.1 \\
\hline 50.019 & 30 & -- & -- & 50.009 & 8.9 & 50.013 & 23.7 \\
\hline 53.411 & 30 & -- & -- & 53.366 & 5.7 & 53.369 & 20.2 \\
\hline
\end{tabular}

Table 2: Lattice constant of Se thin film.

\begin{tabular}{|c|c|c|c|}
\hline \multirow{2}{*}{ Lattice con. ASTM } & \multicolumn{3}{|c|}{ T C $^{\circ}$} \\
\cline { 2 - 4 } & $\mathbf{R . T}$ & $\mathbf{1 0 0}$ & $\mathbf{2 0 0}$ \\
\hline $\mathbf{a}(\mathbf{3 . 6 4 2})$ & -- & 3.150 & 3.156 \\
\hline $\mathbf{c}(\mathbf{5 . 1 4 7})$ & --- & 5.115 & 5.145 \\
\hline
\end{tabular}

Fig. 4 minutes for the surface structure of the building turned out fine in general roughness increases with annealing,there is no evidence of a columnar microstructure from evaporation[13,14]. This agrees with SEM results as it can seem in Fig. 5.

Fig. 6 shows the relationship between optical transmittance and wavelength within the visible (near IR; 550-1200 $\mathrm{nm}$ ) range for samples prepared at different annealing temperature. It is clear from a figure that there are two regions, the first region at wavelengths that are less than $580 \mathrm{~nm}$ full absorption. The second region is the area that appears after $580 \mathrm{~nm}$ and displays my visual transmittance and be clearly linked with annealing.

In fact appears a clear positive effect in transmittance, This wavelength asymptotic length he received researcher Tan [7], increasing in annealing increases as a result of crystallization by the effect of annealing $[15,16]$.

Fig. 7 shows the relationship between Se thin film micro hardness and annealing temperature, also these increased the crystallization and related with increasing the alignment ,integration and adhesion of films with the substrate, this agree with $[17,18,19]$. 


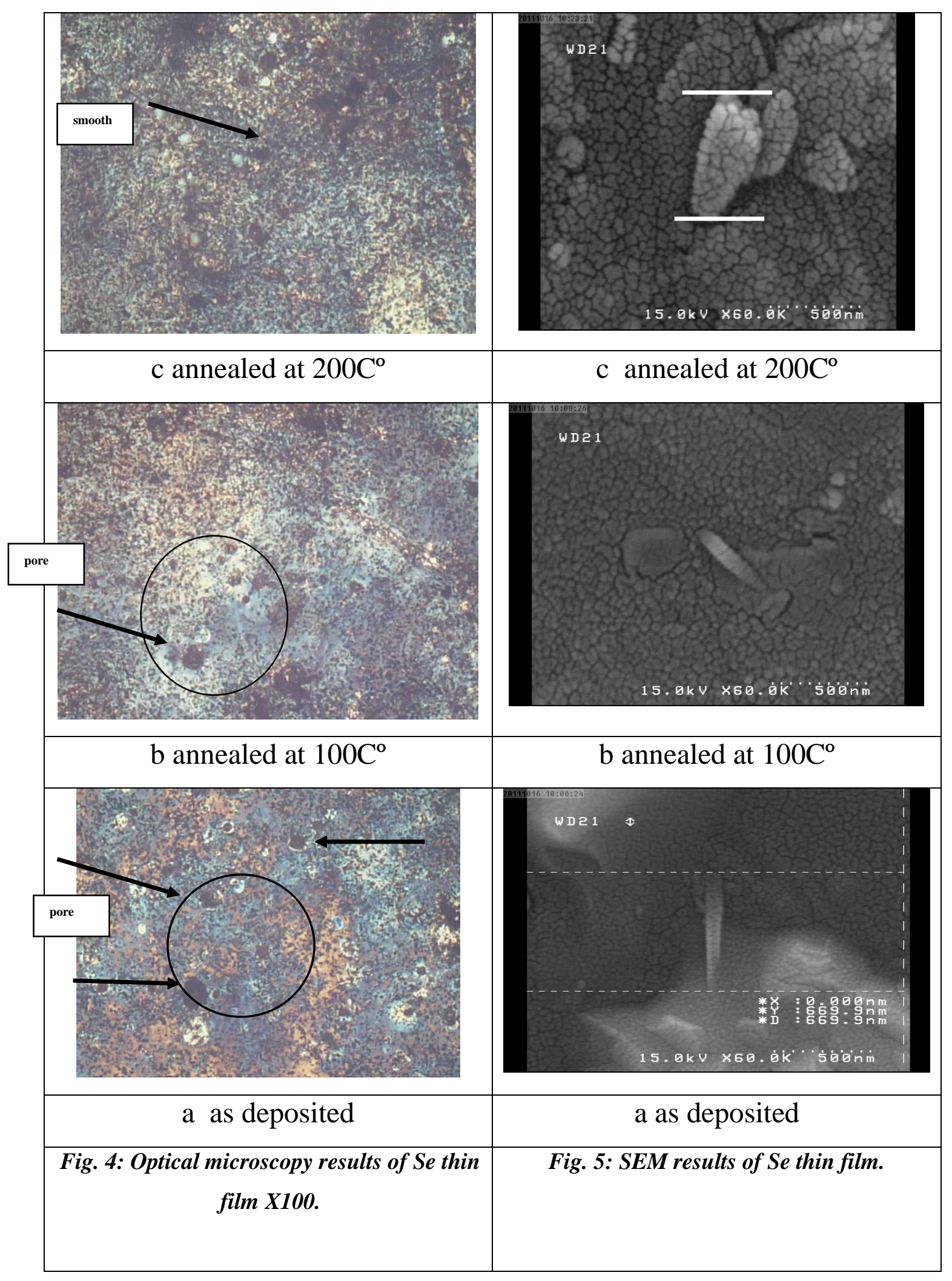



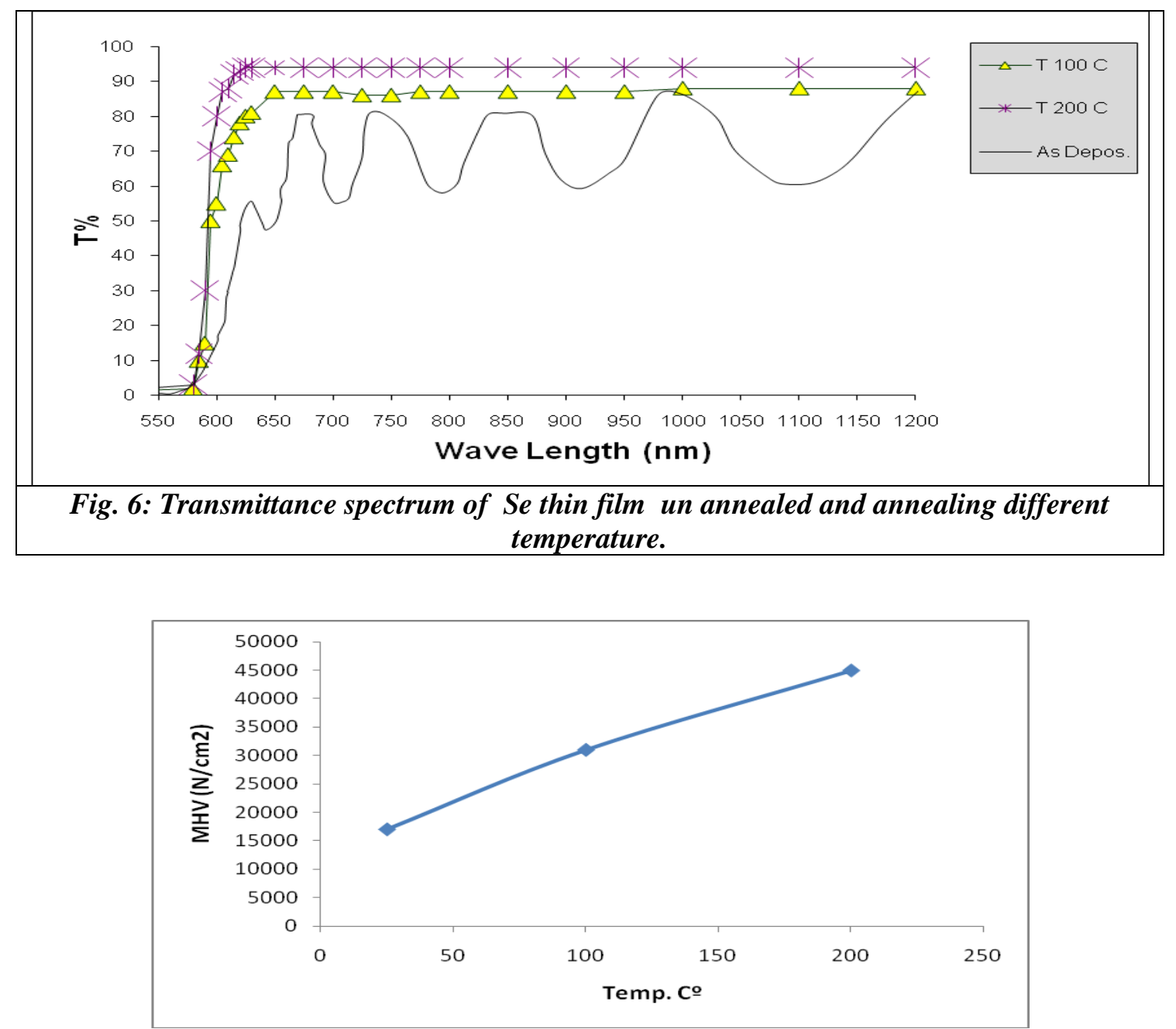

Fig. 7: MHV variation with annealing temperature of Se thin film.

\section{Conclusions}

1- Thin film of selenium transform from an amorphous structure to crystalline after annealing.

2- At the wavelengths least $(580 \mathrm{~nm})$ thin films have $0 \%$ transmittance and with annealing the transmittance will be increased heavily and settles.

3- Increasing the transmittance of thin film due to increase the regularity of the lattice.

\section{References}

[1] L.Ren, Hongzhou Zhang, Pingheng Tan, Yaofeng Chen, Zhensheng Zhang, Yongqin Chang, Jun $\mathrm{Xu}$, Fuhua Yang, and Dapeng
Yu, J. Phys. Chem., B 108(2004) 46274630.

[2] J. Woollam, "Photoconductive and optical properties of amorphous selenium", (NASA) National Aeronautics and Space Administration, 2001.

[3] D. Poelman, R. Van Meirhaeghe, 52, 5-6 (June 1992) 259-264.

[4] B. Pejova, I. Grozdanov, App. Surface Sci., 177 (2001) 152-157.

[5] C. Fella, J. Stückelberger, $H$. Hagendorfer, F. Mattina, L. Kranz, S. Nishiwaki, A. Uhl, Y. Romanyuk, A. Tiwari, Chem. Mater., 26, 3 (2014) 14201425. 
[6] Z. Lu, M. Layani, X. Zhao, L. Tan, T. Sun, S. Fan, Q. Yan, S. Magdassi, H.Hng, "Fabrication of Flexible Thermoelectric Thin Film Devices by Inkjet Printing", Smll., 25 JAN 2014.

[7] W.Tan, "Optical properties of amorphous Selenium Films", MSc Thesis, University of Saskatchewan, 2006.

[8] M. Cabral, M. Calegaro, S. Machado, RSC Advances, 2 (2012) 2498-2503.

[9]E. Schubert, Fred, Light-Emitting Diodes, 2nd edition: Cambridge University Press, 2006.

[10] Y. Sirotin, M. Shaskolskaya, "Fundamentals of Crystal Physics", Mir Publishers, Moscow(1982).

[11] M. Cabral, M. Calegaro, S. Machado, Nanogravimetric study of lead underpotential deposition on selenium thin films as a semiconductor alloy formation procedure, Electronic Supplementary Material (ESI) for RSC Advances, The Royal Society of Chemistry, 2012.

[12] H.K. Pulker, Applied Optics, 18 (1979) 1969.
[13] R. Birkmire \& E. Eser, Annu. Rev. Mater. Sci., 27 (2007) 625-53.

[14] S. Mahboob,S. Malik,N.Haider, C. Nguyen, M.Malik, P.Brien, Journal of Crystal Growth, 394, 15 (May 2014) 39-48. [15] N.Okereke, A. Ekpunobi, Research Journal of Chemical Sciences, 1, 6 (Sept. 2011) 64-70.

[16] A. Feltz, "Amorphous Inorganic Materials and Glasses", VCH Publishers, Inc., New York, NY (USA), 371-372, 1993. [17] D.Strbac, R. Petrović ,S. Petrović , R. Videnović, M. Dramićanin, Materials Science and Technology, 30, 2 (February 2014) 236-240.

[18] H. Kumar, A. Sharma, N. Mehta, Materials Letters, 121, 15 (April 2014) 194197.

[19] F. Ernst, P. Pirouz, Liquid-Phase Deposition of _-CIS Thin Layers Phase I, Annual Report University Cleveland, Ohio, 2004. 